\title{
The Application of the Classification of the Theory of Inventive Problems Solving (Triz) in Textile Design
}

\author{
Santis Sandra $\mathrm{HS}^{1 *}$, Marcicano João $\mathrm{PP}^{2}$, Dedini Franco $\mathrm{G}^{1}$, Held Maria $\mathrm{SB}^{2}$ and Sanches Regina $\mathrm{A}^{2}$ \\ ${ }^{1}$ University State of Campinas, Faculty of Mechanical Engineering, Brazil \\ ${ }^{2}$ University of São Paulo, Department of Textile and Fashion, Brazil
}

*Corresponding author: Sandra H da Silva de Santis, University State of Campinas, Faculty of Mechanical Engineering, FEM, Brasil

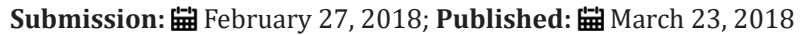

\begin{abstract}
The survey was conducted for the theory analyzes TRIZ (theory of inventive resolution), evaluating its methods, procedures and discussing its proposal for encouraging human creative process through the design methodology and tools for the technological fabric designer. The study identified several alternatives, working with the identification of the features analyzed in the array.
\end{abstract}

Keywords: TRIZ; Creative Process; Tool

\section{Introduction}

The processes should provide the design changes to meet the needs and desires of consumers by definition of product the goals and expected results. Design processes must be sequenced so that all activities are carried out, and in this sense, the knowledge of the functions helps to define the answers in decision making design phase. The purpose is to evolution that functionality to show that requirements are essential to consumers and how it can change the industrial processes in the production of fabric.

Know what is expected, helps to perform and transform, in a general context, objective way to show which needs can be understood and that resources must be used. So, the design can transform and materialize the desires to the desired result.

TRIZ theory is the basis for the development of this study. According to Carvalho \& Back [1], the theory developed by Altshuller [2] in his study on the patents in the period. His approach is differentiated from the others by being focused on the studies of inventive solutions to real problems.

The management in recent years demands for solutions that can improve the operation of the company, using technological inputs, management methodologies, new business models, operational model and functional management. Better performance in the process requires changes in the operating system, the search for new resources and options for modifying the materials and processes.

In theory, the application of the method used by the TRIZ seeks solutions for inventive problems because creativity is an element in various areas of human knowledge, this methodology was born in engineering with the original purpose of developing a method to invent. However, an investigation into the creative process that causes the reflection of this survey and discussion. On the subject, the questions help you comprehend the important aspects of the manufacturing system and aesthetic aspects. This verification is dedicated to examining the procedure for creation of the design in textile manufacture and its relations with the screening of resources, materials, and colors in the object.

The goal is to unravel the mechanisms that guide work in the procedure of creation and textile manufacture, for professional intervention, analyze the influences that govern the creative process. A crucial point of analysis used that address employment issues of project procedures in this practice. What does employ a standardized design methodology or what is inventing new standards? In the act of generating new templates to encourage the creative process, what are the factors that determine the final product? To do this, the study uses qualitative research with quantitative characteristics, mainly by the use of the interviews and questionnaires to investigate the exercise of creating textile manufacture, as well as interdisciplinary resources that work with different fields of knowledge, including design, fashion, aesthetics, and the market economy.

\section{The triz (russian acronym for theory of inventive problem- solution)}

The concept of TRIZ theory promotes idea generation through structured tools, mainly by encouraging creativity. Continuing in 
this context, the TRIZ is a structured procedure for innovation and creativity. With her, organizations will not need to hire "inventive geniuses" or be awarded solely on intuitive human processes to solve their problems.

The TRIZ began to be developed during the years 50, Altshuller in the former USSR studied several patents in different areas, with the aim of seeking more effective alternatives for creative solution of problems than available especially intuitive methods and creative perception problems [1]. Anyway, the theory consists of a set of procedures with the proposed acts of creativity and innovation.
With this theory, organizations don't bother to seek "creative geniuses" in the labor market or even solve problems for lack of creativity of the human intuitive processes, because the methodologies help to solve creative inertia. And yet, inventive principles should propose the best use of elements to produce through the idealization, contradiction, and resources. This method consists in the analysis of component production object seeking to encourage the creative process.

The theory is based on the 40 inventive principles shown in Table 1. Table 1 can be used for modification and encouragement to assist the creative process:

Table 1: The 40 inventive principles.

\begin{tabular}{|c|c|}
\hline Principles of TRIZ & Principles of TRIZ \\
\hline 1. Segmentation & 21. Dispatch quickly \\
\hline 2. Extraction & 22. Turn prejudice into profit \\
\hline 3. Quality in & 23.Feedback \\
\hline 4. Asymmetry & 24. Mediation \\
\hline 5. Union or Mixture & 25. Self Service \\
\hline 6. Universalization & 26. Copy \\
\hline 7. Alignment & 27. Object use discarding \\
\hline 8. Balance & 28. Replace the mechanical means \\
\hline 9. Prior Compensation & 29. Use pneumatic or Hydraulic \\
\hline 10. Prior Action & 30. Use of thin films or membranes \\
\hline 11. Cushioning or protection provided for & 31. Use porous materials \\
\hline 12. Equipotential bonding & 32. Color change \\
\hline 13. Reversal & 33. Thermal voltage \\
\hline 14 Change shapes & 34. Disposal and regeneration \\
\hline 15 Promotion & 35. Change in physical state or chemical \\
\hline 16. Partial or Excessive action & 36. Phase transition \\
\hline 17. Changing dimension & 37. Thermal Expansion \\
\hline 18. Vibration & 38. Use of strong oxidizers \\
\hline 19. Periodic Action & 39. Using inert atmosphere \\
\hline 20. A useful action continuity & 40. Use of composite materials \\
\hline
\end{tabular}

These principles can help you create a new object by encouraging the creative process, they were created to encourage creativity.

In this way, the principles should be used to contribute to the process of creating, building a system to adapt to the standards of the certifications, that conduct and tools are exerted to preserve the quality of products and services.

In this context, the TRIZ consists of a series of procedures of a methodology that encourages the creative process, using tools to support the idea troubleshoot inertia or creative inactivity can be stimulated through modification in structure, instruments of creativity and innovation and continuing the theory introduces a set of measures that modify the object through the division of functions the coordination of actions by changing color, functionality, weight and cost reduction. The analysis of the benefits of the product, component separation and verification of use and disposal.

Botero [3] states in his studies that companies aim to reduce costs and increase the company's results through the application of methods and tools of the quality of the processes. Many companies are looking for solutions that can be tailored to your needs momentary. These manufacturing companies require a management system oriented to the improvement in production, performance, and reduction of losses [4].

Performance improvement in management focuses on functional processes, thus creativity influences the reality of small and medium-sized enterprises by encouraging increased productivity. In this way, the results favorable increase competitive advantage by providing market and compete to obtain greater productivity, are relevant for the company. 
TRIZ theory provides alternatives to assist the creative process and solves complex problems through the inventive principles; this encourages significant changes which can be from the change of composition, exploring the physical state, replacing forms until same modification of components. Several variables are determined in the creation process, due to the complexity and require flexibility.

The component flexibility assists as a predisposition to creativity and has a lot of variability as decision-making, uncertainty, complexity, and ambiguity because it is a choice that is based on the information.

Therefore, this theory of conditions for various change, recreate, modifying the object, and the supplied components giving alternatives to increase creativity through concepts that promote development and improvement.

The resolution of the problem through this theory consists of a structured process uses diverse strategies like a change of functions, the evolution of forms (thorough knowledge of the object to change shapes) and object interaction with the context or the expectation of content.

\section{Creative Process}

The man has his creative manifestations through their individual aspirations, thoughts, and idealization. The need is a motivating factor that drives to the pursuit of knowledge, and satisfaction problem solution. To Lobach [5] "the human being is also addressed by multiple and varied needs. The appearance of needs is not always logical, especially when other activities or processes have an occasional preference ". The need to demand satisfaction, aspiration is the desire to get something spontaneous to prove the idea or the preview. Aspiration is the desire to get something that may or may not be achieved. The needs and follow the evolution of technology, the instruments of information and economic development.

Lobach [5] States that the design consists of a project, plan or systematic method that includes the solution of a problem incorporating ideas, innovation, the creation of sketch, samples, templates to make the concrete solution. Over the centuries, the needs in their evolution have been accompanied by the development of tools, methods, and systems. The constant development through research and events show that the innovative creativity has had a key role. In this sense, the study of the methodology for the development of the creative process entered a logical and rational thinking in human evolution. The development of human creative process has also been marked by various frustrations, problems in creativity and innovation, these problems are reported consistently by various scholars.

A number of scholars and researchers [5] have already been attacked by creative inertia, the difficulty of exposing ideas, fears, lack of innovation or even problems that seemed intractable.

\section{Materials and Methods}

This work was qualified as an exploratory study, using production tools; the research was qualitative whose method of study is to survey data with quantitative characteristics using charts and graphs, with modeling of tests, interviews, and work (loco) [610]. In addition, the use of the data collected by primary source (interview recorded by a digital recorder for analysis purposes) and secondary (bibliography and webliography) that allowed the theoretical and practical support. The proposed methodology for the product design begins with the use of mind mapping creation techniques after the theory TRIZ associated with design tools are utilized to create a model of stimulus to the creative process [11].

How to use the classification method of TRIZ to prioritize functional parameters and properties required in the development of the knitted product for this, we used the linking prioritization matrix properties, characteristics, and classification [12]. Through the focus groups methodology which consists of meeting a set of criteria people in a brainstorming with product development professionals.

Barbosa [6] state that "the groups of outbreaks have advantage allow to obtain in a short time, multiple views of a group of people. The group is composed of people from various categories and textile area contributions: designs, managers, and assistants attached to the process of creation.

The model establishes the analysis proposed in theory by means of idealization, contradiction, and resources for the creation of a technological fabric which can switch the composition to generate innovative products through functionality. In the first step develops the object to the features, this stage is the description of the requirement [13].

To do this, it was compiled a matrix that prioritizes the basic principles for creating a process that encourages creativity in the design of the textile product [14-18]. In the second stage, the design project with the characteristics and the design sketch demonstrating the purpose. In the model, it was used tools to analyze the functions of the product, discover the main features of the object through of the knitted fabric technology [19].

The methodology used to unravel this question is based on the bibliographic research through books, articles, and websites. As the focus of the analysis was chosen the issues surrounding the use of design methodology in practice [20].

\section{Discussion and Results}

The knitted fabric needs features, functionality, and properties that meet the customer's needs. For that to happen, it is important to assess critically each functionality [21].

So, in the design process already starts also the idea of disposing of waste is called on any non-required activity that does not add value to the client. And there is also another sense in relation to the 
material is waste the leftovers and reusable materials [22-26]. The process of manufacturing product development consists of a series of actions to meet the need of the market.

The project methodology is in a series of operations carried out for the development of a product, in which use the tools and methods to assist in the design and construction [27]. In this context, the ideas and information contained in the template are used to examine the correspondence of the specifics needed to evaluate the criteria (Figure 1) must be prioritized in the creative process of the production of smart fabrics.

\begin{tabular}{|c|c|c|c|c|c|c|}
\hline TRIZ Principles/Inventive Factors & Ergonmics & Physical & Mechancal & Aesthetic & Tendences & \\
\hline 3 QualityLocation & 5 & 5 & 5 & 3 & 1 & 19 \\
\hline 5 Streamliningproperties & 5 & 5 & 5 & 3 & 1 & 19 \\
\hline 27 Use andDisposal & 5 & 5 & 3 & 3 & 1 & 17 \\
\hline 4 Asymmetry & 5 & 5 & 3 & 3 & 1 & 17 \\
\hline 40 Use ofcompositematerials & 5 & 5 & 3 & 3 & 1 & 17 \\
\hline 33 Thermal Stress & 5 & 5 & 3 & 3 & 1 & 17 \\
\hline 35 Chance physical or chemical state & 5 & 5 & 3 & 3 & 1 & 17 \\
\hline 1 Segmentationandfragmentation & 5 & 3 & 3 & 3 & 1 & 15 \\
\hline 9 Prior compensation & 5 & 3 & 3 & 3 & 1 & 15 \\
\hline 10 Prior Action & 5 & 3 & 3 & 3 & 1 & 15 \\
\hline 11 Prior Damping & 3 & 3 & 3 & 3 & 1 & 13 \\
\hline 12 Equipotentiality & 3 & 3 & 3 & 3 & 1 & 13 \\
\hline 13 Inversion & 3 & 3 & 3 & 3 & 1 & 13 \\
\hline 14 Esferoidicidade & 3 & 3 & 3 & 3 & 1 & 13 \\
\hline 15 Consolidation & 3 & 3 & 3 & 3 & 1 & 13 \\
\hline 16 partialorexcessiveaction & 3 & 3 & 3 & 3 & 1 & 13 \\
\hline 17 Moving to a new dimension & 3 & 3 & 3 & 3 & 1 & 13 \\
\hline 18 Mechanicalvibration & 3 & 3 & 3 & 3 & 1 & 13 \\
\hline 19 PeriodicAction & 3 & 3 & 3 & 3 & 1 & 13 \\
\hline 20 Continuityofusefulaction & 3 & 3 & 3 & 1 & 1 & 11 \\
\hline 21 Acceleration & 3 & 3 & 3 & 1 & 1 & 11 \\
\hline 22 Losstransformationintoprofit & 3 & 3 & 3 & 1 & 1 & 11 \\
\hline 23 Feedback & 3 & 3 & 3 & 1 & 1 & 11 \\
\hline 24 Mediation & 3 & 3 & 3 & 1 & 1 & 11 \\
\hline 25 Self-service & 3 & 3 & 3 & 1 & 1 & 11 \\
\hline 26 Copy & 3 & 3 & 3 & 1 & 1 & 11 \\
\hline 37Thermal Expansion & 3 & 3 & 1 & 1 & 1 & 9 \\
\hline 28 Substitutionmechanicalmeans & 3 & 3 & 1 & 1 & 1 & 9 \\
\hline 29 Pneumaticorhydraulicconstruction & 3 & 1 & 1 & 1 & 1 & 7 \\
\hline 30 Use of thin films and flexible membranes & 3 & 1 & 1 & 1 & 1 & 7 \\
\hline 31 Use ofporousmaterials & 3 & 1 & 1 & 1 & 1 & 7 \\
\hline 32 Color change & 3 & 1 & 1 & 1 & 1 & 7 \\
\hline 8 Balance & 3 & 1 & 1 & 1 & 1 & 7 \\
\hline 34 Disposalandregeneration & 3 & 1 & 1 & 1 & 1 & 7 \\
\hline 7 Nesting & 3 & 1 & 1 & 1 & 1 & 7 \\
\hline 36 PhaseChange & 3 & 1 & 1 & 1 & 1 & 7 \\
\hline 6 Universal & 3 & 1 & 1 & 1 & 1 & 7 \\
\hline 38 Use strongoxidizers & 3 & 1 & 1 & 1 & 1 & 7 \\
\hline 39 Use ofinertatmospheres & 3 & 1 & 1 & 1 & 1 & 7 \\
\hline \multirow[t]{2}{*}{2 Extraction } & 3 & 1 & 1 & 1 & 1 & 7 \\
\hline & 140 & 110 & 96 & 78 & 40 & \\
\hline
\end{tabular}

Figure 1: Priority 3 array.

Source: Santis(2016) 
The group analyzed the attributes of fabric and the principles of TRIZ are related in the array to get an intersection a few points, they must be prioritized for the design of a technological fabric, ordering for meaning and relevance, the needs of the properties and the functionality required [28].

The matrix was used to perform a cross-check and analysis of information about technological fabrics. Crossed the characteristics of the fabric with the principles with this can obtain the possibilities of changes in materials: thermal properties (absorb heat or turn up the heat, cold or heat), physical properties (have the stipulated format or preset), mechanical properties (conductive circuits of information, conduct stimuli activate electrically conducting elements, etc.), aesthetic aspects (color change, shape memory, outline the body etc.) and fashion trends [29].

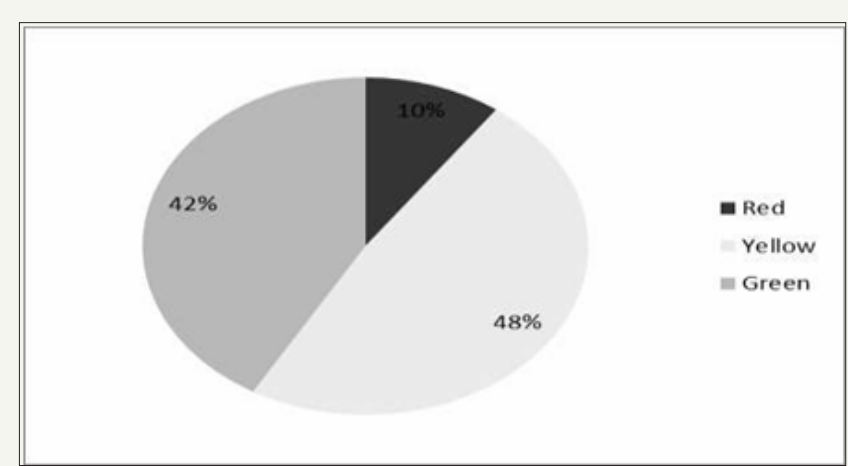

Figure 2: Priorities in percentage.

Source: Santis (2016)

The chart in Figure 2 shows the relative frequency observed, provides viewing of the priorities found in the matrix, only $10 \%$ of existing correlations between the principles of TRIZ and the attributes of the fabric are important and can be modified, the difference between medium and low priority accounts for only $6 \%$, and the sliced medium priority with $48 \%$ and the low priority with $42 \%$ [30].

Valuable information presented in the array consists of the representation of the ergonomic features, physical properties and mechanical properties on the aesthetic aspects and tendency as tissues because these elements can be modified in the objects.

Another aspect, can be observed by examining the principles of TRIZ theory one can realize that as priorities: quality, rationalization of properties, use and disposal, asymmetry, use of composite materials, thermal stress, change in State, segmentation or fragmentation, chemical, or physical compensation provided are the main changes that infer innovation to the object.

Notice that each of these principles is an opportunity of fabric modification, a possibility of change in the functionality and the value of the product [31,32]. These are relevant to the creative process in the technological fabric because they provide options for the development and modification of the product.

The map showed in Figure 3 shows in detail what solutions should be changed to the development of the production process, provides an extension based on the principles of TRIZ that must be executed, and that resources must be changed for each property the decomposition of the function of the product and the required properties are analyzed, which promotes the demonstration of the interrelationships between the functions, parameters, and characteristics of the process.

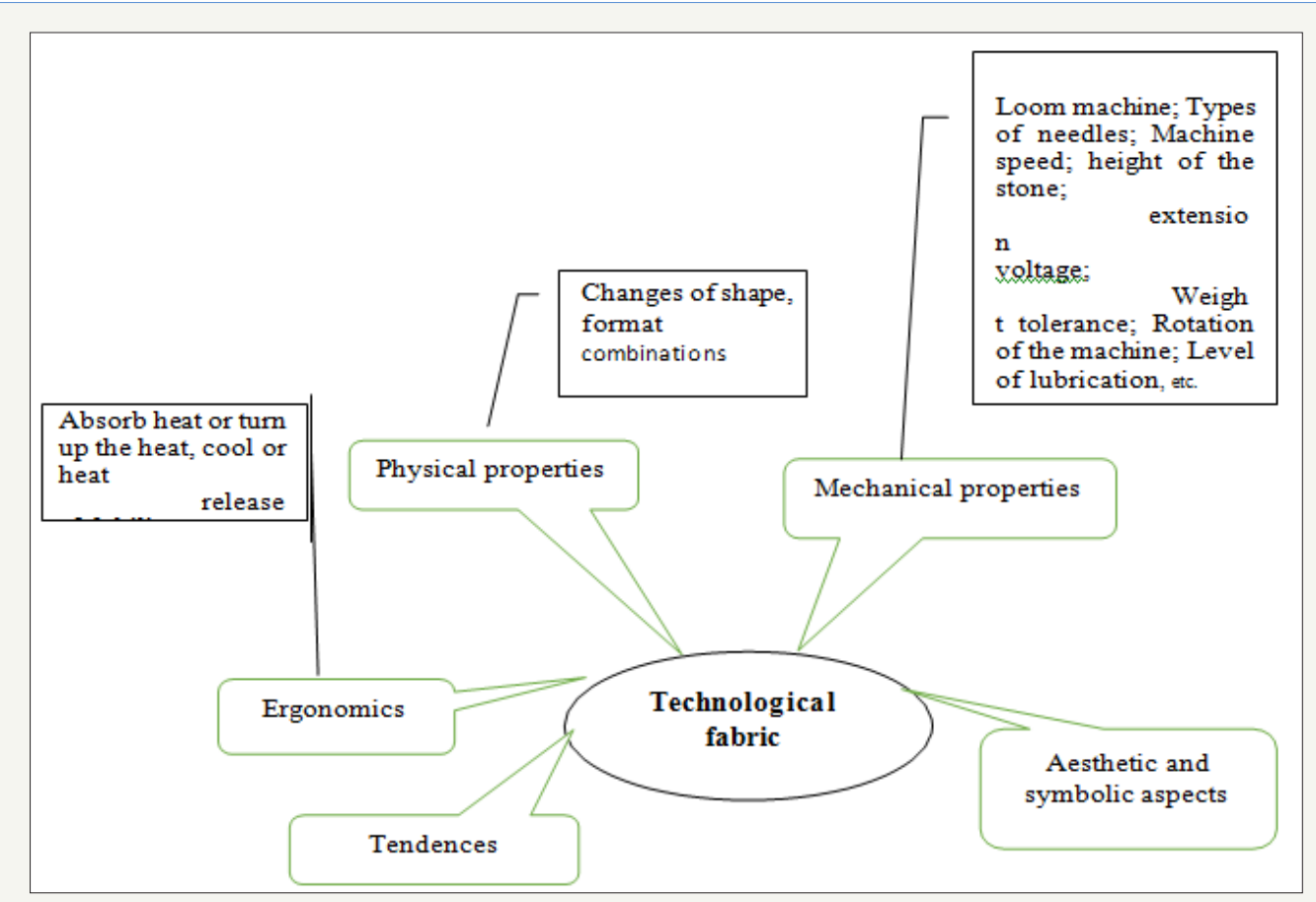

Figure 3: Solution map. 


\section{Final Considerations}

With the application of correspondence array or priority array can be prioritized the elementary inputs, combining the necessary resources [33]. An array of correspondence was structured to demonstrate how priorities cause each element group prioritized back to your experience and didn't notice the really was important to the creative process.

In this model include the prioritization of properties and principles of TRIZ that can encourage the creative and innovation process, starting from the modifications that can be made in the design of the fabric. In this context, the array was adapted for use, this array is generally used in strategy for risk definition.

The proposal of the array is the identification of principles to obtain the template applies the solution to perform packet prioritization properties together principles of TRIZ, this tool encourages the creative and innovation process, from the detailed diagram of changes that must be made in the design of the fabric. In this context, the map translates the needs listed in the array. The proposal of the array consists of identifying the principles to obtain the characteristics or parameter and the map shows the solution that must be executed.

In addition, the matrix helps to define what functions should be modifying, which properties are required to satisfy customer need and what can be changed to add value to the functionality of the product, this part of the strategies to improve the creative process.

This strategy applied in conjunction with the appropriate tool helps the operating parameters of the related technological fabrics. This promotes a conducted investigation of the needs and intentions of customers, including product generation process, assessment of inputs, required functionality, management costs, controls, and functions of the operation. The use of the tools gives support due to the construction of the product generation process. Thus, the operation should provide the solution for the generation, creativity, and innovation, and still provide alternatives to conflict dilemmas between the usefulness, ergonomics, and usability.

Therefore, the use of these tools can expand, diagrammatic (show through diagrams and graphics) and organize the creative process by collaborating with creativity and innovation.

\section{References}

1. Carvalho, Marco Aurélio, Back Nelson (2001) Use of the fundamental concepts of TRIZ and the method of inventive principles in the development of products. In: Brazilian congress of product development management.

2. Altshuller G (2002) 40 Principles: TRIZ keys to innovation. Technical Innovation Center.

3. Botero PAG (2010) Lean Manufacturing: flexibilidad, agilidad y productividad. Gestión \& Sociedad 3(2): 75-88

4. Mesquita M (2001) Skills for Continuous Improvement of Production: a case study in companies of the auto parts industry. Dissertation (Master in Production Engineering) - Federal University of São Carlos, São Carlos, Brazil.
5. Lobach B (2001) Industrial design: Bases for configuration. Rio de Janeiro, Edgard Blücher Ltda, Brazil, p. 208.

6. Barbosa S, Silva B (2010) Human-computer interaction. Rio de Janeiro: Elsevier Brazil, Brazil.

7. Agostinho OL (2012) Manufacturing Systems. vol. I \& vol. II, Course Apostilas, State University of Campinas.

8. Barbará SE (2011) Process management. Rio de Janeiro: Qualitymark.

9. Bezerra GM, Martins SB (2013) Ergonomics equation in clothing design: body space, modeling and materials.

10. Campos, Vicente Falconi, (1992) Total quality control. Rio de Janeiro: Cristiano Ottoni Foundation, Brazil.

11. Chai KH, Zhang J, Tan KC (2005) A TRIZ-based method for new service design. Journal of Service Research 8(1): 48-66.

12. Csillag JM (2012) Value analysis: value methodology: value engineering, value management, cost reduction, administrative rationalization, $\left(4^{\text {th }}\right.$ edn), São Paulo, Brazil.

13. Dalla costa A, Souza Santos ED (2011) Creative economy: new opportunities based on intellectual capital. Economia \& Tecnologia, Curitiba 7: $179-186$

14. Dedini FG (2007) Design of mechanical systems. Handout of the course EM 964 of the Faculty of Mechanical Engineering of Unicamp. p. 179

15. Gadd K (2011) TRIZ for engineers: enabling inventive problem solving. John wiley \& sons, USA.

16. Howkins J, Griesi A (2013) Economia criativa. M. Books, São Paulo, Brazil.

17. Juran JM, translation of Nivaldo Montinelli Jr (2004) Quality from the project: new steps for quality planning in products and services. São Paulo: Ed. Pioneira Thomson Learning, p. 15

18. Machado RM (2009) From the cultural industry to the creative economy. 9: 83-95.

19. Mann, Darrell (2001) An introduction to TRIZ: The theory of inventive problem solving. Creativity and Innovation Management 10(2): 123125.

20. Mean-shen L (2011) The study of green product design and development by applying TRIZ innovation principles. African Journal of Business Management 5(18): 7740 .

21. Menegucci F, Martins E, Menezes M, Santos FA (2012) Experiment Textiles and Innovation in Fashion Design. In: 8th Colloquium of Fashion, Rio de Janeiro, Brazil.

22. Ostrower F (1978) Creativity and creation processes.

23. Pires VS, Albagli S (2009) Business strategies, informational dynamics and brand identity in the creative economy.

24. Porter ME (1996) Competitive Advantage: Creating and Sustaining Superior Performance. Rio de Janeiro: Campus, Brazil.

25. Rantanen K, Ellen D (2010) Simplified TRIZ: New problem solving applications for engineers and manufacturing professionals. CRC press, USA.

26. Ruchti B, Livotov P (2001) TRIZ-based innovation principles and a process for problem solving in business and management. The TRIZ Journal 1: 677-687.

27. Sanches RA (2010) Technology applied to articles of clothing intended for sports.

28. Santis Sandra HS (2016) The use of design methodology tools for the creative process in textile products-ENPMODA 2016-National Meeting of Fashion Research-School of Arts, Sciences and Humanities-University of São Paulo. 
29. Santis Sandra HS (2016) Project methodology applied to smart fabrics. Journal of Textile and Fashion Technology (JTFT) 2(1): 7-18.

30. Santis Sandra HS (2016) Strategy of textile design: use of design methodology tools in the creative process. Strategic Design Research Journal 10.

31. Savransky SD (2000) Engineering of creativity: Introduction to TRIZ methodology of inventive problem solving. CRC Press, USA.
32. Smith RE (2011) Application of lean manufacturing tools in cash centres to improve operational efficiency. Tese de Doutorado.

33. Valle Roger, Oliveira, Saulo Barbará 2012) Analysis and Business Process modeling notation focus BPMN (Business Process Modeling Notation). São Paulo: Atlas.
Creative Commons Attribution 4.0 International License

For possible submissions Click Here

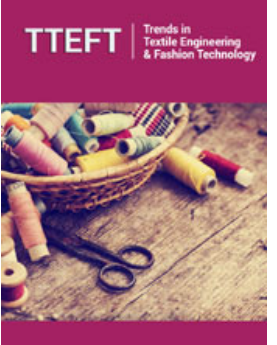

Trends in Textile Engineering \& Fashion Technology

\section{Benefits of Publishing with us}

- High-level peer review and editorial services

- Freely accessible online immediately upon publication

- Authors retain the copyright to their work

- Licensing it under a Creative Commons license

- Visibility through different online platforms 